Jurnal Agroteknologi, Vol. 7 No. 2, Februari $2017: 1$ - 8

\title{
PERTUMBUHAN DAN KERAGAAN TANAMAN JERUK KEPROK BORNEO PRIMA PADA DOSIS PUPUK DAN BENTUK PANGKAS BERBEDA
}

\author{
(Growth and Tree Architecture of Borneo Prima Mandarin Citrus on Different Fertilization Dose and \\ Pruning Form)
}

TIARA SEPTIROSYA ${ }^{1}$, ROEDHY POERWANTO ${ }^{2}$, ABDUL QADIR $^{2}$

${ }^{1}$ Fakultas Pertanian dan Peternakan, UIN Suska Riau

Jl. H. R. Soebrantas Km 15, Pekanbaru

${ }^{2}$ Fakultas Pertanian, Institut Pertanian Bogor

Jl. Meranti, Kampus IPB Darmaga, Bogor

Email: tiaraseptirosya@rocketmail.com

\begin{abstract}
Borneo Prima Mandarin (Citrus reticulata cv Borneo Prima) is a new local commodity that grown in lowland but has an interesting orange skin. As a new commodity, Borneo Prima Mandarin has to be developed in order to reduce citrus import. The research was conducted in lowland area $(250 \mathrm{~m}$ above sea level) IPB research station, Sindang Barang, Bogor from February 2014 to February 2015. The aim of this research was to observe the effect of phosphorus $(P)$ and potassium $(K)$ fertilizer and pruning on the growth and performance of the plants. This research used Randomize Complete Block Design (RCBD) with two factors. The first factor was application of PK fertilizer (15 g P+ $10 \mathrm{~g} \mathrm{K,} 15 \mathrm{~g}$ $P+15 \mathrm{~g} \mathrm{~K}, 20 \mathrm{~g} \mathrm{P}+10 \mathrm{~g} \mathrm{~K}, 20 \mathrm{~g} \mathrm{P}+15 \mathrm{~g} \mathrm{~K}$ per plant) and the second factor was pruning form (without pruning, open center pruning and hedge pruning). The result showed that the combination of phosporus and potassium fertilizer just gave a significant effect to number of shoot. The highest number of new shoots formed by fertilizing $15 \mathrm{~g} \mathrm{P+10} \mathrm{g} \mathrm{K}$ per tree per application. Pruning treatments had significant effect to plant architecture (i.e reduce plant height, land occupation). Open center pruning and hedge pruning made the crown more open that can increase the light interception so that increase the rate of photosynthesis.
\end{abstract}

Keywords: hedge pruning, open center pruning, phosphorus, potassium, shoot

\section{PENDAHULUAN}

Konsumen Indonesia memiliki kecenderungan menyukai jeruk dengan kulit berwarna jingga (Shanti, 2007) yang tidak banyak diproduksi oleh petani Indonesia. Jeruk dengan warna kulit kuning-jingga hanya dapat diproduksi di daerah dataran tinggi yang luasnya semakin terbatas, sehingga kebutuhan terhadap jeruk berwarna jingga sebagian besar dipenuhi melalui impor. Indonesia tercatat sebagai pengimpor jeruk terbesar kedua di Asia Tenggara setelah Malaysia, terutama untuk komoditas jeruk keprok (Hanif \& Zamzami 2011). Volume impor jeruk di Indonesia mengalami peningkatan setiap tahunnya. Berdasarkan data Direktorat Jenderal Hortikultura (2017) volume impor jeruk Indonesia dari 2014 hingga 2016 secara berturut-turut 22.772 ton, 23.827 ton dan 26.313 ton per tahun. Volume impor jeruk ini diperkirakan akan terus meningkat seiring dengan meningkatnya kesadaran masyarakat akan kebutuhan gizi seimbang.

Salah satu upaya untuk mengurangi impor jeruk nasional ialah dengan meningkatkan produktivitas dan kualitas jeruk berwarna jingga di Indonesia. Jeruk Keprok Borneo Prima merupakan salah satu komoditas hortikultura unggulan baru di Kalimantan Timur, yang memiliki keunggulan sebagai jeruk keprok dataran rendah dengan kulit buah berwarna jingga (BPPMD Kaltim, 2009). Sebagai komoditas baru, teknik budidaya yang diterapkan masih berdasarkan pengalaman petani ataupun mengikuti teknik budidaya jeruk jenis lain. Penelitian perlu dilakukan untuk memperoleh teknik budidaya terbaik agar tanaman dapat tumbuh optimum sehingga dapat menghasilkan jeruk dengan kualitas dan kuantitas yang baik.

Dosis pemupukan yang tepat merupakan salah cara untuk meningkatkan pertumbuhan tanaman yang belum berproduksi (Alcantara et al. 2011; Hifni et al. 2013). Rasmussen dan Smith (1961) menyatakan bahwa tujuan pemupukan tanaman jeruk yang belum berproduksi ialah untuk mendapatkan pertumbuhan tanaman yang baik. Pertumbuhan tanaman harus ditunjang oleh keragaan tanaman yang ideal. Menurut Durand et al. (2005) keragaan 
tanaman merupakan hasil pengulangan yang terjadi pada proses pertumbuhan dan percabangan tanaman. Keragaan tanaman jeruk yang ideal adalah tanaman dengan bentuk tajuk yang terbuka sehingga matahari dapat masuk ke seluruh bagian tajuk. Jeruk Borneo Prima memiliki bentuk tajuk yang tidak membuka, dimana percabangannya mengarah ke atas sehingga perlu dilakukan pemangkasan untuk meningkatkan intersepsi cahaya matahari ke tajuk. Menurut Krajewski dan Krajewski (2011) pemangkasan dilakukan untuk mengatur pertumbuhan tunas dan membentuk kanopi tanaman untuk memperoleh struktur pohon yang kuat dan memaparkan daun terhadap sinar matahari secara optimal.

\section{BAHAN DAN METODE}

Penelitian dilaksanakan di Kebun Percobaan IPB Sindang Barang, Desa Sindang Barang, Kecamatan Bogor Barat, Kota Bogor, Jawa Barat pada bulan Februari 2014 hingga Februari 2015. Lokasi penelitian merupakan daerah dataran rendah dengan ketinggian tempat $250 \mathrm{mdpl}$.

Bahan yang digunakan adalah tanaman jeruk keprok Borneo Prima belum menghasilkan berumur tiga tahun, pupuk SP$36\left(36 \% \mathrm{P}_{2} \mathrm{O}_{5}\right)$, dan pupuk $\mathrm{KCl}(60 \% \mathrm{~K})$. Peralatan yang digunakan ialah gunting pangkas, meteran, hand counter, leaf area meter (LiCor 3000) dan portable photosynthesis system (LiCor 6400).

$$
\text { Penelitian ini menggunakan }
$$

Rancangan Acak Kelompok faktorial, dosis pupuk $\mathrm{P}$ dan K $(15 \mathrm{~g} \mathrm{P}+10 \mathrm{~g} \mathrm{~K}, 15 \mathrm{~g} \mathrm{P}+15 \mathrm{~g}$ $\mathrm{K}, 20 \mathrm{~g} \mathrm{P}+10 \mathrm{~g} \mathrm{~K}, 20 \mathrm{~g} \mathrm{P}+15 \mathrm{~g} \mathrm{~K}$ per tanaman) sebagai faktor pertama dan bentuk pangkas (tanpa pemangkasan, pangkas terbuka tengah, pangkas pagar) sebagai faktor kedua. Pada penelitian ini diperoleh 12 kombinasi perlakuan yang diulang sebanyak empat kali, sehingga terdapat 48 satuan percobaan dengan satu tanaman untuk masing-masing satuan percobaan.

Pelaksanaan penelitian dimulai dengan persiapan bahan tanam sebelum aplikasi pemupukan dan pemangkasan, meliputi pemilihan tanaman contoh, pelabelan dan penyiangan gulma yang tumbuh di bawah tegakan tanaman. Aplikasi pemupukan (N,P dan $\mathrm{K}$ ) dan pemangkasan dilakukan setiap tiga bulan, yakni pada Maret (periode 1), Juni (periode 2), September (periode 3) dan Desember (periode 4). Tanaman diberi pupuk $P$ dan $K$ sesuai dengan dosis perlakuan yang telah ditentukan, sedangkan untuk pupuk $\mathrm{N}$ semua tanaman diberi dosis yang sama yakni $20 \mathrm{~g} \mathrm{~N} /$ pohon/aplikasi.

Pada pangkas terbuka tengah, dipilih dan dipelihara tiga percabangan yang kuat dan letaknya tidak berdekatan (membentuk sudut $90-120^{\circ}$ satu dengan yang lain). Cabangcabang yang lain dipangkas sehingga membentuk tiga cabang primer dan setiap cabang primer dipelihara tiga cabang sekunder. Pada pangkas terbuka tengah juga dilakukan pengendalian dominasi apikal dengan cara memangkas batang utama yang tumbuh tegak. Pemangkasan dilakukan dari ujung batang utama hingga $5-10 \mathrm{~cm}$ di dekat percabangan yang akan dipelihara.

Pada pangkas pagar, percabangan yang tumbuh di arah Timur dan Barat dipangkas, sedangkan percabangan yang tumbuh pada arah Utara dan Selatan tetap dipertahankan. Cabang-cabang yang tumbuh dibagian Utara dan Selatan diatur dan diikatkan ke sebilah kayu atau bambu dengan menggunakan tali. Cabang diikat dengan sedikit longgar sehingga tidak merusak dan mengganggu pertumbuhan cabang. Pemangkasan dilakukan dari ujung batang utama hingga $3-5 \mathrm{~cm}$ di dekat percabangan yang akan dipelihara.
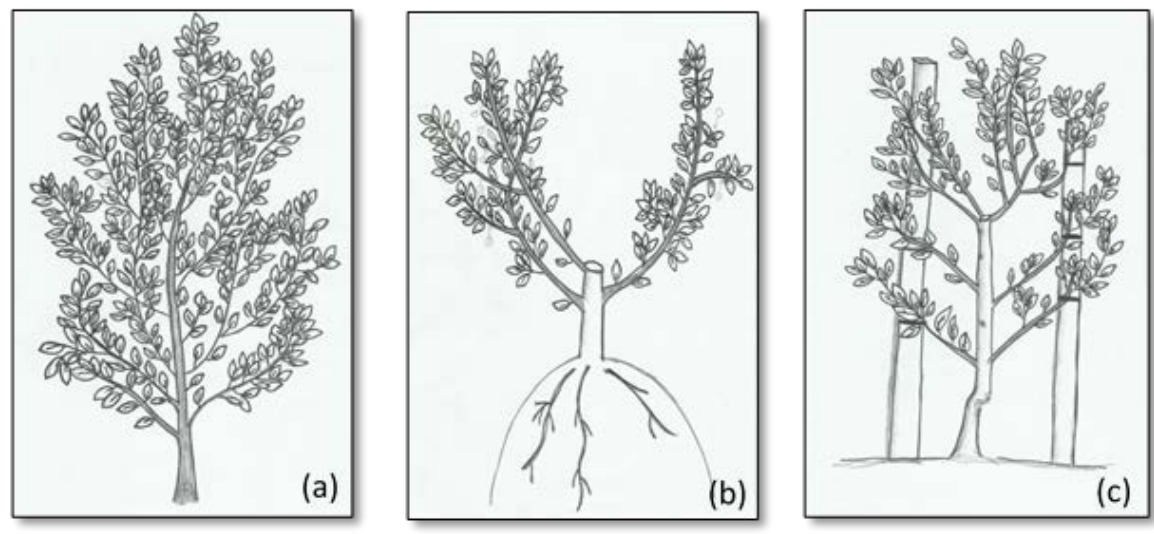

Gambar 1 Sketsa bentuk pemangkasan jeruk keprok Borneo Prima (a) tanpa pemangkasan,

(b) pangkas terbuka tengah dan (c) pangkas pagar 
Pengamatan dilakukan terhadap 3 komponen, yaitu pertumbuhan tanaman, keragaan tanaman, serta intersepsi cahaya dan fotosintesis. Jumlah tunas dan daun baru yang muncul merupakan parameter yang diamati untuk melihat pertumbuhan vegetatif tanaman. Pengamatan terhadap jumlah tunas dan daun baru dilakukan satu minggu setelah tanaman diberi perlakuan. Pada komponen keragaan tanaman diamati tinggi tanaman dan panjang tajuk arah Utara - Selatan dan Barat Timur pada setiap periode pertumbuhan tunas serta indeks luas daun (ILD) dan tingkat kehijauan daun pada akhir penelitian. Pada komponen intersepsi cahaya dan fotosintesis diamati intensitas cahaya, laju transpirasi, laju fotosintesis dan konduktansi stomata pada akhir penelitian.

\section{HASIL DAN PEMBAHASAN}

Berdasarkan hasil analisis data yang telah dilakukan, tidak terdapat interaksi antara perlakuan pemupukan dan pemangkasan. Pada percobaan ini hanya terdapat pengaruh faktor tunggal pada setiap parameter pengamatan yang dilakukan.

Tabel 1 Jumlah tunas dan daun baru tanaman jeruk keprok Borneo Prima pada dosis pemupukan $\mathrm{P}$ dan $\mathrm{K}$ serta bentuk pangkas yang berbeda

\begin{tabular}{|c|c|c|c|c|c|c|c|c|}
\hline \multirow[b]{3}{*}{ Perlakuan } & \multicolumn{8}{|c|}{ Periode pertumbuhan tunas ke- } \\
\hline & \multicolumn{2}{|c|}{1} & \multicolumn{2}{|c|}{2} & \multicolumn{2}{|c|}{3} & \multicolumn{2}{|c|}{4} \\
\hline & $\begin{array}{l}\text { Jumlah } \\
\text { tunas }^{a}\end{array}$ & $\begin{array}{l}\text { Jumlah } \\
\text { daun }^{a}\end{array}$ & $\begin{array}{l}\text { Jumla } \\
\mathrm{h} \\
\text { tunas }^{\mathrm{a}}\end{array}$ & $\begin{array}{l}\text { Jumlah } \\
\text { daun }^{a}\end{array}$ & $\begin{array}{l}\text { Jumla } \\
\mathrm{h} \\
\text { tunas }^{\text {a }}\end{array}$ & $\begin{array}{l}\text { Jumlah } \\
\text { daun }^{a}\end{array}$ & $\begin{array}{c}\text { Jumla } \\
\text { h } \\
\text { tunas }^{\text {a }}\end{array}$ & $\begin{array}{l}\text { Jumlah } \\
\text { daun }^{a}\end{array}$ \\
\hline \multicolumn{9}{|c|}{$\begin{array}{l}\text { P dan K } \\
\text { (g/pohon/aplikasi) }\end{array}$} \\
\hline $15 P+10 K$ & $41,97^{\mathrm{a}}$ & 269,45 & $22,33^{\mathrm{a}}$ & $174,00^{\mathrm{a}}$ & $9,00^{a}$ & 68,00 & 27,08 & 210,67 \\
\hline $15 P+15 K$ & $27,17^{\text {ab }}$ & 216,83 & $15,25^{\mathrm{b}}$ & $120,00^{b}$ & $3,83^{b}$ & 27,83 & 26,92 & 193,00 \\
\hline $20 P+$ & $21,58^{\mathrm{b}}$ & 176,36 & $17,25^{\mathrm{b}}$ & $134,17^{\mathrm{b}}$ & $5,67^{\mathrm{ab}}$ & 45,33 & 25,67 & 207,00 \\
\hline $\begin{array}{l}20 \mathrm{P}+15 \mathrm{~K} \\
\text { Pemangkasan }\end{array}$ & $21,33^{\mathrm{b}}$ & 160,67 & $17,00^{\mathrm{b}}$ & $128,67^{\mathrm{b}}$ & $5,82^{\mathrm{ab}}$ & 41,64 & 20,00 & 150,50 \\
\hline $\begin{array}{l}\text { Tanpa } \\
\text { pemanqkasa }\end{array}$ & 26,13 & 211,43 & $13,56^{\mathrm{b}}$ & $135,63^{\mathrm{ab}}$ & $1,06^{\mathrm{c}}$ & $10,63^{b}$ & $13,06^{b}$ & $130,63^{\mathrm{b}}$ \\
\hline Terbuka tengah & $2 \varepsilon$ & 229,50 & $20,06^{\mathrm{a}}$ & $160,50^{\mathrm{a}}$ & $11,50^{\mathrm{a}}$ & $92,00^{\mathrm{a}}$ & $35,06^{\mathrm{a}}$ & $280,50^{\mathrm{a}}$ \\
\hline Pagar & 29,19 & 175,13 & $20,25^{\mathrm{a}}$ & $121,50^{\mathrm{b}}$ & $5,67^{\mathrm{b}}$ & $34,00^{b}$ & $26,63^{\mathrm{a}}$ & $159,75^{\mathrm{b}}$ \\
\hline
\end{tabular}

Ket : Angka-angka pada kolom yang sama diikuti oleh huruf yang sama tidak berbeda nyata pada taraf uji 5\% (uji selang berganda Duncan)

Perbedaan kombinasi dosis pemupukan $\mathrm{P}$ dan $\mathrm{K}$ memberikan pengaruh nyata terhadap pertumbuhan tunas tanaman jeruk keprok Borneo Prima (Tabel 1). Secara umum aplikasi $15 \mathrm{~g} P$ yang dikombinasikan dengan $10 \mathrm{~g} \mathrm{~K}$ menghasilkan jumlah tunas terbanyak dibandingkan kombinasi pemupukan $\mathrm{P}$ dan $\mathrm{K}$ yang lain. Jumlah tunas yang tumbuh pada aplikasi $15 \mathrm{~g} \mathrm{P}$ dan $10 \mathrm{~g} \mathrm{~K}$ disetiap periode pertumbuhan tunas ialah 42 tunas (periode pertumbuhan tunas 1), 22 tunas (periode pertumbuhan tunas ke 2), 9 tunas (periode pertumbuhan tunas ke 3 ) dan 27 tunas (periode pertumbuhan tunas ke 4). Hasil penelitian yang sama juga dilaporkan oleh Boughalleb et al. (2011) bahwa pemupukan $\mathrm{P}$ dan $\mathrm{K}$ dengan dosis yang tepat pada tanaman jeruk belum menghasilkan dapat meningkatkan parameter pertumbuhan tanaman, diantaranya jumlah daun dan tunas.

Pada Tabel 1 juga menunjukkan bahwa pemangkasan memberikan pengaruh nyata terhadap jumlah tunas dan daun baru.
Pangkas terbuka tengah yang diaplikasikan pada tanaman jeruk keprok Borneo Prima dapat menghasilkan tunas lebih banyak dibandingkan perlakuan pangkas lainnya pada periode pertumbuhan tunas ke 3 . Hal ini sejalan dengan hasil penelitian Dhaliwal et al. (2013) dan Sharma et al. (2014) terhadap jeruk Kinnow (Citrus reticulata Blanco) menyebutkan bahwa pemangkasan tanaman memiliki jumlah tunas yang lebih banyak dan mempercepat munculnya tunas baru. Tunastunas baru tersebut muncul dari cabang primer dan sekunder. Melalui pemecahan dormansi yang terinisiasi oleh pemangkasan, tunastunas baru akan muncul dan berkembang menjadi daun-daun baru yang menggantikan daun-daun yang hilang karena pemangkasan. Semakin banyak jumlah tunas yang terinisiasi maka diharapkan akan semakin tinggi produksi buah jeruk, namun penangkapan cahaya matahari pada tanaman tersebut tetap optimum. 
Tabel 2. Tinggi tanaman jeruk keprok Borneo Prima pada pemupukan $\mathrm{P} K$ dan bentuk pangkas berbeda

\begin{tabular}{|c|c|c|c|c|}
\hline \multirow{2}{*}{ Perlakuan } & \multicolumn{4}{|c|}{ Tinggi tanaman pada periode ke- } \\
\hline & 1 & 2 & 3 & 4 \\
\hline & \multicolumn{4}{|c|}{ Tinggi tanaman $(\mathrm{cm})^{\mathrm{a}}$} \\
\hline \multicolumn{5}{|l|}{$\begin{array}{l}\text { Pemupukan P dan K } \\
\text { (g/pohon/apliaksi) }\end{array}$} \\
\hline $15 P+10 K$ & 64,35 & 72,27 & 103,67 & 123,50 \\
\hline $15 P+15 K$ & 63,66 & 74,98 & 120,33 & 132,83 \\
\hline $20 P+10 K$ & 56,13 & 66,55 & 105,42 & 124,40 \\
\hline $20 P+15 K$ & 56,18 & 67,59 & 105,42 & 129,75 \\
\hline \multicolumn{5}{|l|}{ Pemangkasan } \\
\hline Tanpa pemangkasan & 66,36 & $77,16^{\mathrm{a}}$ & $125,56^{\mathrm{a}}$ & $158,13^{a}$ \\
\hline Pangkas terbuka tengah & 57,26 & $66,83^{\mathrm{b}}$ & $99,56^{\mathrm{b}}$ & $111,19^{\mathrm{b}}$ \\
\hline Pangkas pagar & 56,58 & $66,54^{\mathrm{b}}$ & $101,00^{\mathrm{b}}$ & $115,07^{\mathrm{D}}$ \\
\hline Interaksi & tn & tn & tn & tn \\
\hline
\end{tabular}

Pertambahan tinggi tanaman lebih dipengaruhi oleh faktor pemangkasan (Tabel 2). Tanaman jeruk keprok Borneo Prima memiliki tunas yang arah pertumbuhannya menghadap ke atas yang menyebabkan ukuran tanaman semakin tinggi. Pemangkasan merupakan salah satu cara untuk mengendalikan dominasi apikal pada tanaman ini. Menurut Coombs et al. (1994) pemangkasan dapat mematahkan dominansi apikal pada tunas dan mendorong pertumbuhan tunas lateral, sehingga arah pertumbuhan tunas menjadi ke samping yang secara langsung dapat memperlambat peningkatan tinggi tanaman. Berdasarkan Tabel 2 bahwa tanaman yang tidak dipangkas memiliki ukuran tanaman yang lebih tinggi dibandingkan tanaman yang diberi perlakuan pemangkasan. Perlakuan pemangkasan yang dilakukan membuat ukuran tanaman menjadi lebih pendek.

Tabel 3. Panjang tajuk tanaman jeruk keprok Borneo Prima pada dosis pemupukan $\mathrm{P}$ dan $\mathrm{K}$ serta bentuk pangkas berbeda

\begin{tabular}{lcccccccc}
\hline & \multicolumn{9}{c}{ Utara - Selatan } \\
\cline { 2 - 8 } \multicolumn{1}{c}{ Perlakuan } & \multicolumn{9}{c}{ Panjang Tajuk pada Periode Pertumbuhan Tunas ke- } \\
& $\mathbf{1}$ & $\mathbf{2}$ & $\mathbf{3}$ & $\mathbf{4}$ & $\mathbf{1}$ & $\mathbf{2}$ & $\mathbf{3}$ & $\mathbf{4}$ \\
\hline $\begin{array}{l}\text { Pemupukan P dan K } \\
\text { (g/pohon/aplikasi) }\end{array}$ & & & & & & & & \\
15 P + 10 K & 44,75 & 53,75 & 60,08 & 67,00 & 39,04 & 49,42 & 57,33 & 56,42 \\
15 P + 15 K & 39,48 & 53,33 & 63,92 & 63,58 & 35,38 & 49,00 & 51,58 & 52,17 \\
20 P + 10 K & 35,75 & 52,42 & 60,67 & 61,50 & 34,18 & 39,67 & 51,42 & 51,40 \\
20 P + 15 K & 40,49 & 44,25 & 49,42 & 60,50 & 33,58 & 40,92 & 50,75 & 48,67 \\
\hline Pemangkasan & & & & & & & & \\
Tanpa & & & & & & & & \\
pemangkasan & 40,59 & $59,88^{\mathrm{a}}$ & 62,88 & $72,00^{\mathrm{a}}$ & $44,76^{\mathrm{a}}$ & $56,06^{\mathrm{a}}$ & $59,38^{\mathrm{a}}$ & $71,27^{\mathrm{a}}$ \\
Terbuka tengah & 38,82 & $47,63^{\mathrm{b}}$ & 53,88 & $61,19^{\mathrm{b}}$ & $38,59^{\mathrm{a}}$ & $43,25^{\mathrm{b}}$ & $52,86^{\mathrm{ab}}$ & $53,69^{\mathrm{b}}$ \\
Pangkas pagar & 40,94 & $45,31^{\mathrm{b}}$ & 58,81 & $56,60^{\mathrm{b}}$ & $23,28^{\mathrm{b}}$ & $34,94^{\mathrm{b}}$ & $46,06^{\mathrm{b}}$ & $31,53^{\mathrm{c}}$ \\
\hline Interaksi & tn & tn & tn & tn & tn & tn & tn & tn \\
\hline
\end{tabular}

Ket : Angka-angka pada kolom yang sama diikuti oleh huruf yang sama tidak berbeda nyata pada taraf uji 5\% (uji selang berganda Duncan)

Berdasarkan Tabel 3 dapat dilihat bahwa tanaman yang tidak dipangkas memiliki tajuk lebih panjang, baik tajuk arah utaraselatan maupun barat-timur pada periode pertumbuhan tunas ke 2 dan 4, jika dibandingkan tanaman yang tidak dipangkas. Pangkas pagar menjadikan tajuk yang tumbuh di bagian barat-timur menjadi lebih pendek dibandingkan perlakuan pemangkasan lainnya. Hal ini disebabkan oleh pemangkasan yang telah dilakukan, tunas-tunas yang tumbuh arah Barat - Timur dipangkas dan tunas-tunas yang ada di Utara - Selatan dibiarkan tumbuh. Tujuannya ialah agar cahaya matahari dapat masuk ke dalam tajuk secara optimum dari matahari terbit di pagi hari hingga terbenam di 
sore hari. Penerimaan cahaya matahari yang optimal pada tajuk akan mempengaruhi fotosintesis.

Aplikasi pangkas pagar mengokupasi daerah pertanaman arah Barat - Timur lebih sempit dibandingkan tanaman jeruk keprok Borneo Prima yang tumbuh alami tanpa aplikasi pemangkasan. Okupasi arah Barat Timur yang lebih sempit ini dapat menghemat jarak tanam, sehingga jeruk dapat ditanam lebih rapat pada arah tersebut dan populasi tanaman jeruk per hektarnya menjadi lebih banyak. Aplikasi pangkas pagar dapat mengurangi setengah dari jarak tanam arah Barat - Timur, sehingga pemangkasan tipe ini sesuai untuk diterapkan pada lahan berukuran sempit, seperti pekarangan rumah. Munandar
(2001) melaporkan bahwa produktivitas yang tinggi dapat dicapai dengan produksi per pohon yang tinggi dengan jarak tanam besar atau produksi per pohon sedang tetapi jarak tanamnya kecil.

Daun merupakan organ tanaman utama dalam proses fotosintesis. Permukaan daun yang luas dan datar memungkinkan penangkapan cahaya yang maksimal. Tabel 4 menunjukan bahwa pemupukan $\mathrm{P}$ dan $\mathrm{K}$ serta pemangkasan pada semua taraf perlakuan tidak memberikan pengaruh nyata terhadap indeks luas daun tanaman jeruk keprok Borneo Prima. Tanaman yang tidak dipangkas cenderung memiliki ILD lebih besar dibandingkan tanaman yang dipangkas.

Tabel 4 Indeks luas daun tanaman jeruk keprok Borneo Prima pada dosis fosfor dan kalium serta bentuk pangkas berbeda

\begin{tabular}{lc}
\hline Perlakuan & Indeks Luas Daun (ILD) \\
\hline Pemupukan P dan K & \\
(g/pohon/aplikasi) & \\
$15 \mathrm{P}+10 \mathrm{~K}$ & 0,36 \\
$15 \mathrm{P}+15 \mathrm{~K}$ & 0,49 \\
$20 \mathrm{P}+10 \mathrm{~K}$ & 0,38 \\
$20 \mathrm{P}+15 \mathrm{~K}$ & 0,45 \\
Pemangkasan & \\
Kontrol & 0,45 \\
Pangkas terbuka tengah & 0,37 \\
Pangkas pagar & 0,44 \\
\hline Interaksi & tn \\
\hline
\end{tabular}

Hal ini sejalan dengan penelitian Munandar (2001) dan Rahayu (2014) yang menunjukkan bahwa pemangkasan yang diaplikasikan pada tanaman dapat menurunkan ILD lebih rendah dibandingkan tanaman yang tidak dipangkas. Tanaman yang tidak dipangkas memiliki jumlah daun lebih banyak dan luas okupasi lahan lebih tinggi dibandingkan tanaman yang dipangkas sehingga nilai ILD lebih tinggi. Tanaman yang dipangkas memiliki jumlah daun yang lebih sedikit akibat pemangkasan sehingga okupasi lahan lebih rendah dan nilai ILD rendah.

Tabel 5 Laju fotosintesis, laju transpirasi dan konduktansi stomata jeruk keprok Borneo Prima pada dosis pupuk $\mathrm{P}$ dan $\mathrm{K}$ serta bentuk pangkas yang berbeda

\begin{tabular}{lcccc}
\hline \multicolumn{1}{c}{ Perlakuan } & $\begin{array}{c}\text { Laju } \\
\text { Fotosintesis } \\
\left(\mu \mathrm{mol} \mathrm{CO}_{2} \mathrm{~m}^{-2} \mathrm{~s}^{-1}\right)\end{array}$ & $\begin{array}{c}\text { Laju } \\
\text { Transpirasi } \\
\left(\mathrm{mmol} \mathrm{H}_{2} \mathrm{O} \mathrm{m}^{-2} \mathrm{~s}^{-1}\right)\end{array}$ & $\begin{array}{c}\text { Konduktansi } \\
\text { Stomata } \\
\left(\mathrm{mol} \mathrm{H}_{2} \mathrm{O} \mathrm{m}^{-2} \mathrm{~s}^{-1}\right)\end{array}$ & $\begin{array}{c}\text { Suhu Daun } \\
\left({ }^{\circ} \mathrm{C}\right)\end{array}$ \\
\hline $\begin{array}{l}\text { Pemupukan P K } \\
\text { (g/phon/aplikasi) }\end{array}$ & & & & \\
15 P + 10 K & 67,59 & 12,07 & 0,45 & 30,38 \\
$15 \mathrm{P}+15 \mathrm{~K}$ & 67,11 & 13,76 & 0,58 & 29,96 \\
$20 \mathrm{P}+10 \mathrm{~K}$ & 58,41 & 12,76 & 0,54 & 30,38 \\
20 P + 15 K & 62,50 & 13,00 & 0,52 & 30,12 \\
Pemangkasan & & 12,90 & 0,53 & 30,08 \\
Tanpa pemangkasan & 64,40 & 13,00 & 0,49 & 30,55 \\
Terbuka tengah & 61,45 & 12,79 & 0,54 & 30,00 \\
Pangkas pagar & 64,99 & $\mathrm{tn}$ & $\mathrm{tn}$ & $\mathrm{tn}$ \\
\hline Interaksi & $\mathrm{tn}$ & & & \\
\hline
\end{tabular}

Laju fotosintesis menentukan jumlah asimilat yang terbentuk (fotosintat) pada tanaman. Menurut Gardner et al. (2008) faktorfaktor yang berpengaruh secara langsung 
dalam proses fotosintesis ialah cahaya, $\mathrm{CO}_{2}$ dan suhu. Tabel 5 menunjukkan pemupukan $\mathrm{P}$ dan $\mathrm{K}$ serta pemangkasan tidak memberikan pengaruh nyata terhadap laju fotosintesis, transpirasi maupun konduktansi stomata. Hal ini diduga karena suhu daun yang juga tidak menunjukkan perbedaan yang nyata antar perlakuan. Menurut Vu dan Yelenosky (1987) kapasitas fotosintesis daun sangat dipengaruhi oleh suhu tanaman. Nasaruddin et al. (2006) menambahkan bahwa daun secara langsung akan mempengaruhi buka tutup stomata. Peningkatan suhu dalam batas tertentu akan merangsang bukaan stomata untuk menyerap $\mathrm{CO}_{2}$, yang merupakan bahan baku utama dalam proses fotosintesis. Peningkatan $\mathrm{CO}_{2}$ memacu peningkatan laju fotosintesis.

Pada Tabel 5 juga menunjukkan bahwa pemangkasan tidak berpengaruh nyata terhadap laju fotosintesis, laju transpirasi, konduktansi stomata dan suhu daun. Secara umum dapat dilihat bahwa tanaman yang diaplikasikan pangkas pagar memiliki laju fotosintesis yang lebih tinggi dibandingkan perlakuan pemangkasan lainnya. Semakin tinggi laju fotosintesis maka akan semakin tinggi jumlah fotosintat yang dapat dihasilkan tanaman.

\section{KESIMPULAN DAN SARAN}

\section{Kesimpulan}

1. Aplikasi $15 \mathrm{~g} P$ yang dikombinasikan dengan $10 \mathrm{~g} \mathrm{~K}$ merupakan dosis pemupukan terbaik untuk tanaman jeruk keprok Borneo Prima belum menghasilkan

2. Aplikasi pangkas terbuka tengah dan pangkas pagar menjadikan tajuk tanaman lebih terbuka dan mengurangi okupasi lahan.

\section{Ucapan Terima Kasih}

Penelitian ini dibiayai oleh Hibah Riset Insentif berjudul 'Pengembangan Jeruk Unggulan Indonesia Guna Pemenuhan Kebutuhan Gizi Masyarakat dan Penghematan Devisa Negara Tahun II' dan SPK Nomor Kontrak 25/SEK/INSINAS/PPK/I/2014 tanggal 27 Januari 2014.

\section{DAFTAR PUSTAKA}

Alcantara, B.M., A. Quinones., E.P. Millo. and F. Legaz. 2011. Nitrogen Remobilization Response to Current Supply in Young Citrus Trees. Plant and soil, 324 (1): 433 $-443$.

Boughalleb, F., M. Mhamdi and H. Hajlaoui. 2011. Response of Young Citrus Trees to NPK Fertilization Under Greenhouse and Field Conditions. Agricultural Journal, 6 (3): 66-73.

[BPPMD Kaltim] Badan Perumahan dan Penanaman Modal Daerah Propinsi Kalimantan Timur. 2009. Investasi Budidaya Jeruk Borneo Prima. Samarinda (ID): BPPMD.

Coombs, D., P. Blackburne-Maze, M. Cracknell and R. Bentley. 1994. The Complete Book of Pruning. The Bath Press. Great Britain (UK).

Dhaliwal, H.S., L.K. Sharma., A.K. Banke., J.S. Brar and S.K Bali. 2013. Investigations on Growth of 'Kinnow' (Citrus reticulata) Mother Plants Pruned at Different Intensities. Middle-East Journal of Scientific Research, 16 (1): 135-140.

Direktorat Jenderal Hortikultura. 2015. Impor Komoditi Pertanian Subsektor Hortikultura 2014. http://hortikultura. pertanian.go.id. Diakses pada tanggal 27 Agustus 2015.

Durand, J.B., Y. Guedon., Y. Caraglio and E. Costes. 2005. Analysis of the Plant Architecture via Tree-structured Statistical Models: the Hidden Markov Tree Models. New Physiologist, 166: 813-825.

Gardner, F.P., R.B. Pearce, R.L. Mitchell. 2008. Fisiologi Tanaman Budidaya. Volume ke-1. Susilo, H., penerjemah. UI Press. Terjemahan dari Physiology of Crop Plants.

Hanif, Z. dan L. Zamzami. 2011. Trend Jeruk Impor dan Posisi Indonesia sebagai Produsen Jeruk Dunia. Dalam Prosiding Workshop Rencana Aksi Rehabilitasi Agribisnis Jeruk Keprok SoE yang Berkelanjutan untuk Substitusi Impor di Nusa Tenggara Timur.

Krajewski, A. J. and S. A. Krajewski. 2011. Canopy Management of Sweet Orange, Grapefruit, Lemon and Mandarin Trees in the Topisc: Principles, Practices and Commercial Experiences. Acta Hort, 894: $65-76$.

Munandar, A. 2001. Studi Arsitektur pohon dalam hubungannya dengan pertumbuhan dan perkembangan durian. Disertasi. Institut Pertanian Bogor. Bogor (ID).

Poerwanto R., dan A.D. Susila. 2014. Teknologi Hortikultura. IPB Press- Bogor.

Rahayu, R. Dan R. Poerwanto. 2014. Optimasi Pertumbuhan Vegetatif dan Keragaan Tanaman Jeruk Keprok Borneo Prima (Citrus reticulata cv. Borneo Prima) melalui Pemangkasan dan Pemupukan. J. Hort. Indonesia, 5 (2): 95-103.

Shanti, S.I. 2007. Analisis Keputusan Konsumen dalam Mengkonsumsi Jeruk 
Lokal dan Jeruk Impor di Ritel Modern (Kasus Konsumen Giant Botani Square Bogor). Skripsi. Institut Pertanian Bogor. Bogor (ID).

Sharma D.H., A.K. Banke., L.K. Sharma and S.K. Bali. 2014. Impact of pruning practices on shoot growth and bud production in Kinnow (Citrus reticulata Blanco) plants. J. of Exp Biol and Agr Scienc, 1(7): 508-513.

Hifni., H.A, M.A. Fahmy., G.A. Bagdady., G.A. Abdrabboh and A.E. Hamdy. 2013. Effect of nitrogen fertilization added at various phenological stages on growth, yield and fruit quality of valencia orange trees. Nature and Science, 11 (12): 220 - 229.

Rasmussen, G.K. and P.F. Smith. 1961. Evaluation of fertilizer practices for young orange trees. Florida State Horticultural Society. Florida (US).

Vu J.C.V. and G. Yelenosky. 1987. Photosynthetic characteristic in leaves of valencia orange (Citrus sinensis (L.) Osbeck) grown under high and low temperature regimes. Environmental and Experimental Botany, 27 (3): $279-287$. 
Pertumbuhan dan Keragaan Tanaman Jeruk Keprok Borneo Prima (Tiara Septirosya, dkk) 